\title{
IMAGEM FOTOGRÁFICA: A COMPLEXIDADE DO PERCURSO DE OTLET AOS DIAS ATUAIS
}

\begin{abstract}
Resumo: Este artigo se propõe a discorrer sobre os usos e apropriações da fotografia, identificando o percurso que fez com que ela passasse de uma invenção do século XIX, com traços puramente estéticos de representação da realidade, para uma ferramenta útil e eficaz da pesquisa acadêmica; aponta para as mudanças ocorridas no conceito de história, ocasionadas pelas transformações que abalaram o pensamento filosófico e científico referentes às fontes documentais e dentre elas a fotografia. Como uma revisão de literatura, este estudo aborda o conceito de documento e sua ampliação, trazendo o pensamento de Briet (1951), Buckland (1991) e Otlet (1996), como referências históricas de um novo pensar sobre a noção de documento. Revista como instrumento de promoção e circulação social do conhecimento, a fotografia passou a ser considerada como um elemento de contribuição teórica aos estudos e análises da sociedade, ao exercer e ser reconhecida a sua função mediadora entre os sujeitos e o mundo, estatuto que repercutiu na adoção de novos olhares e métodos de análise e interpretação que, na contemporaneidade, têm sido adotados por parte das Ciências Sociais e, em particular, pela Ciência da Informação.
\end{abstract}

Palavras-chave: Fotografia - História. Fotografia como documento.

\section{PHOTOGRAPHIC IMAGE: THE COMPLEXITY OF OTLET'ROUTE TO THE CURRENT DAYS}

\begin{abstract}
This article proposes to discuss the uses and appropriations of photography, identifying the path that made it go from an invention of the 19th century, with purely aesthetic features of the representation of reality, to a useful and effective tool for academic research. It points to the changes that have occurred in the concept of history, caused by the transformations that have shaken philosophical and scientific thinking, referring to documentary sources and, among them, photography. As a literature review, this study addresses the concept of document and its expansion, bringing the thought of Briet (1951), Buckland (1991) and Otlet (1996), as historical references for a new thinking about the notion of document. Photographed as an instrument for the promotion and social circulation of knowledge, photography came to be considered as an element of theoretical contribution to the studies and analyzes of society, by exercising and recognizing its mediating function between subjects and the world, a status that had repercussions on adoption new perspectives and methods of analysis and interpretation that, nowadays, have been adopted by the Social Sciences and, in particular, by the Information Science.
\end{abstract}

Keywords: Photography - History. Photography as a document. 


\section{INTRODUÇÃo}

Em resumo a prática e as produções fotográficas migraram do restrito território do útil para o da cultura e da arte. [...] Mudaram as práticas e as produções, os lugares e os circuitos de difusão, bem como as formas, os valores, os usos, os autores. (ROUILLÉ, 2009, p. 15)

De uma invenção do século XIX, caracterizada pelos traços puramente documentais de representação da realidade, até sua utilização como ferramenta eficaz de análise da sociedade e da cultura, a fotografia percorreu um trajeto em paralelo com a mudança no conceito de documento. Para compreender essas mudanças, foi preciso traçar um percurso que a situasse em diferentes contextos. Aquele que se propõe a considerá-la uma evidência histórica, uma ilustração; aquele que amplia o seu conceito, revendo a primazia atribuída aos textos escritos; aquele em que a fotografia passa a ser considerada um instrumento da pesquisa científica, para a qual é dada uma significância que andou pari passu com as mudanças do próprio conceito de documento.

Tangenciar fatos já narrados e que remontam às origens do caminho trilhado nas transformações ocorridas nesse trajeto, fez-se necessário. A princípio, foi dada à fotografia uma diversidade de usos que, historicamente, remetem-na à função de documento social. Os estudos de Gisele Freund (2006), as pesquisas empreendidas por Bourdieu e colaboradores (2003) sobre a relação das práticas sociais com as técnicas e as funções sociais que dela são advindas, referendam este estudo, bem como o pensamento de André Rouillé (2009) que vê a fotografia além do documento, como um produto e uma forma de expressão. Como a fotografia tem sido considerada documento pela Ciência da Informação, recorre-se aos conceitos de Paul Otlet (1996), ${ }^{1}$ a releitura que dele é feita por Suzanne Briet (1951), a Buckland (1997), Bucceroni e Pinheiro (2009), Ortega e Lara (2010) e Manini (2011) que lançam luzes sobre a questão.

Fatores sociais determinantes do valor documental da fotografia são levantados por Gisele Freund (2006, p. 7), estudiosa da fotografia, quando analisa as relações estabelecidas entre a sociedade e as formas artísticas. Ela chama a atenção para o fato de que as mudanças na estrutura social influenciam as expressões artísticas e culturais de uma época, tanto que, no

\footnotetext{
${ }^{1}$ Estamos usando a edição do Traité de Documentation: le livre sur le livre, em espanhol, editada em 1996. A referência completa encontra-se no ítem Referências.
} 
século XIX, na era da máquina e do capitalismo moderno, uma série de procedimentos causaram mudanças significativas na evolução da arte e a fotografia contribuiu, decisivamente, para essa evolução. Afirma a autora que:

Es el típico médio de expresión de uma sociedad, estabelecida sobre la civilización tecnológica, consciente de los objetivos que se asigna, de mentalidad racionalista [cujo] poder de reproducir exactamente la realidad externa - poder inherente a su técnica - le presta um caracter documetal y la presenta como el procedimiento de reproducir más fiel y más imparcial de la vida social. (FREUND, 2006, p. 8)

Suzan Sontag (2004), no seu livro Sobre fotografia, também relata que, acatada pela burguesia a invenção da técnica fotográfica foi ao encontro dos anseios da classe burguesa; justificando, relembra que a câmera possibilitou que o mundo fosse duplicado exatamente no momento em que a sociedade vive um ritmo de transformações vertiginoso. Enquanto "[...] um número incontável de manifestações da vida biológica e social está sendo destruído, em um breve espaço de tempo, surge um instrumento capaz de registrar o que está desaparecendo." (SONTAG, 2004, p. 15).

Quando a questão se volta à legitimação artística e cultural da fotografia, lembra-nos Rouillé (2009, p. 15) que esta vem sendo reconhecida não só em conformidade com as recentes mudanças sociais, mas também como uma consequência da transformação nos meios de comunicação, os avanços tecnológicos e as novas concepções de arte. No livro $A$ fotografia: entre documento e arte contemporânea, ele atesta que:

\footnotetext{
A legitimidade cultural e artística da fotografia é recente [...] Substituiu-se o uso prático do dispositivo pela atenção sensível e consciente prestada às imagens. Mudaram-se as práticas e as produções, os lugares e os circuitos de difusão, bem como as formas, os valores os usos e os autores. (ROUILLÉ, 2009, p. 15).
}

Tais assertivas apontam para o fato de que, desde o seu advento, a fotografia foi considerada uma ferramenta utilitária, capaz de captar a realidade, o que viabilizava o seu uso prático e a sua inserção na dinâmica da sociedade industrial e que só recentemente a mais universal das linguagens plásticas do mundo, como a considera $\mathrm{o}$ autor, tem sido culturalmente legitimada, além do caráter documental que lhe foi atribuído.

\section{O COMPLEXO PERCURSO}

No século XIX, a sociedade buscava uma forma de representação do mundo que atendesse aos seus anseios, aos modos de organização social, política, e ao nível do crescimento e avanço tecnológico atingido. A representação da realidade e dos sujeitos ficava 
a cargo da pintura. Do olhar, da imaginação, da sensibilidade do artista. Uma arte restrita e acessível à aristocracia e a uma abonada classe social que surgia. Foi a fotografia a melhor resposta a esse anseio e a essa necessidade, cuja legitimidade se ancora nas suas funções documentais, pensamento comungado por Bucceroni e Pinheiro (2009, p. 2), quando afirmam que a "[...] sua objetividade confere, de forma unânime, um papel determinante como documento desde o seu advento."

Podia-se não só captar os momentos, gestos, acontecimentos, atitudes dos homens e da natureza, como também retê-los, guardá-los, armazená-los. Era possível provar e comprovar o acontecido. O papel da fotografia se restringia a conservar o traço do passado, auxiliar as ciências, uma testemunha do que foi, cujo poder de informar e propagar foi sendo utilizado cada vez mais.

A função documental atribuída à fotografia, nas primeiras décadas do século XIX, esteve a mercê de ideologias e da manipulação política. Usada como instrumento de vigilância incriminadora e de controle social, nos idos de 1871, ela serviu para a identificação, pela polícia, de trabalhadores que lutaram na Comuna de Paris os quais, identificados, foram assassinados, segundo declaração de Cora Gamarnik (2011) quando discorre sobre os usos sociais da fotografia durante as primeiras décadas de sua história.

A fotografia é marcada, nesse tempo, pela busca de identidade da classe burguesa, pela documentação e instrumentalização das ciências, pela astronomia, pela fisiologia, além de ser utilizada por pseudociências com a finalidade de registrar e classificar características de humanos que poderiam apontar para desvios ou inclinações psicológicas. Acabava por servir a um campo movediço da criminalidade. A superestimação da capacidade referencial da fotografia, levada ao extremo, fez com que ela fosse considerada um instrumento capaz de satisfazer o desejo e a necessidade de uma sociedade que ansiava ver o mundo sem fronteiras e sem deformação.

Não se abria a possibilidade de uma observação parcial desse mundo por parte dos fotógrafos ou mesmo pelo dispositivo que lhes era acessível. Tanto é que nos idos de 1855, segundo Rouillé (2009), o esforço empreendido por Alphonse Bertillon, na Chefatura de Polícia de Paris, era voltado à regulamentação dos procedimentos fotográficos, com a mais pura precisão, no sentido de "[...] extrair dos corpos dos delinquentes algo diferente daquilo que retratistas sabem ver. Leva seu empreendimento tão a sério que o lugar que ocupa não é mais o de fotógrafo [...] mas o lugar de um policial à frente de um arquivo.” (ROUILLÉ, 
2009, p. 203).

Esse fato é citado também por Dubois (2012), quando analisa algumas ficções fotográficas na iconografia científica da segunda metade do século XIX. Chama a atenção para o fato de que nasce com Bertillon um sistema de esquadrinhamento do corpo, de identificação antropométrica que acabou por se constituir numa "rede sócio-coercitiva, uma rede administrativo-policial" em que a fotografia, usada como um meio facilitador das especulações fisiognômicas,

[...] precede de uma espécie de 'estética do desaparecimento' e do apagamento que vai com força contra essa concepção difundida demais segundo a qual a fotografia seria um ápice do real, um excesso de singularidade existencial, uma pura manifestação do visível imediato, em suma dependeria de uma estética da presença irresistível do real e da inscrição do referente. (DUBOIS, 2012, p. 247).

A mecanização da produção da imagem fotográfica, no século XIX, trouxe a reboque a racionalização e a aceleração do seu processo de produção, no entanto, não trouxe consigo nenhuma modificação no que tange à representação do homem e do mundo, muito menos o seu acolhimento como fonte de informação. Nesse contexto, as imagens fotográficas eram utilizadas por pesquisadores e historiadores com finalidade totalmente ilustrativa. Os fatos históricos eram baseados nos documentos escritos que, por serem considerados verdadeiros, não eram questionados criticamente. As imagens serviam, apenas, para confirmar o que os documentos escritos registravam. A historiografia praticada no século XIX se baseava na coleta e na pesquisa dos documentos escritos, considerados oficiais, aos quais eram aplicados métodos rígidos de análise e interpretação em busca da sua autenticidade e que, disponibilizados, de forma ordenada, eram tomados como verdadeiras fontes fidedignas dos acontecimentos

Foram as mudanças advindas das transformações ocorridas no final do século XIX e início do século XX, a respeito do conceito de documento e sua ampliação, visto agora como instrumento de promoção e circulação social do conhecimento, que determinaram um novo pensar sobre a fotografia e seu valor documental, passando a ser considerada como fonte de informação para as Ciências Humanas e Sociais. A sua apropriação e uso por disciplinas como a História, a Antropologia, a Sociologia, a Ciência da Informação seguiram percursos que fizeram com que ela passasse de uma invenção do século XIX, com traços estéticos e documentais de representação da realidade, para uma ferramenta útil e eficaz de análise social e fonte de informação. 
O debate em relação ao uso da fotografia como elemento para análise da pesquisa histórica foi estabelecido em consonância com alterações ocorridas no âmbito da própria História, da corrente historiográfica da École des Annales, surgida na primeira metade do século XX. Esta propunha validar a fotografia não só como documento, mas como subsídio a estudos historiográficos sobre a sociedade e suas respectivas práticas.

Destacam-se, no pantheon dessa corrente de historiadores, as figuras de Lucien Febvre e Marc Bloch, fundadores da revista Annales d'historie économique et sociale, veículo disseminador da ideia de descentralizar a história dos grandes feitos e atentar para os fatos cotidianos, para o homem comum e seu comportamento. Segundo Le Goff (2003), o objetivo era rever a concepção de história, promover a aproximação entre as Ciências Humanas, passando da fase dos debates teóricos para a aproximação com a realidade cotidiana, bem como rever métodos e técnicas nos quais os documentos passam a ser considerados como fontes de informação que presentificam o passado.

Para os estudiosos dos Annales, a investigação histórica deveria ampliar o leque documental para além dos registros escritos e orais, contexto no qual a fotografia passa a ser compreendida como documento e registro válido para o estudo da disciplina História. Esta se descentraliza dos grandes feitos e passa a dar atenção aos fatos cotidianos, ao homem comum, à coletividade e seu comportamento, passando a considerar não só os documentos escritos, mas a oralidade e as imagens como fontes credenciadas de informação e reconstituição da memória.

Por sua característica, desde a gênese, de documentar o real, pessoas, fatos, os acontecimentos e mudanças sociais, a fotografia foi incluída nesse processo de transformação e as funções já exercidas por ela passaram a ser (re)conhecidas e valorizadas. Avaliando os testemunhos sobre o passado, possibilitados pelas imagens fotográficas, Peter Burke (2004) as considera fontes que apoiam as evidências dos documentos escritos e que viabilizam o acesso a aspectos do passado, inalcançáveis por outras fontes.

No âmbito da História, semelhantes formas de conceituar o documento, além da escrita e dos registros gráficos, encontram em Peter Burke (2004) um defensor, ao ressaltar que no final dos anos de 1960, do século XX, uma "virada pictórica" fez com que o valor das fotografias subsidiasse a construção da história social do século XIX, a partir do cotidiano e de experiências de pessoas comuns, virada que ajudou a História a construir "uma história a partir debaixo." Tais alterações passaram a considerar a fotografia detentora de uma sintaxe 
própria, ao se estabelecerem novos conceitos de realidade, outras modalidades metodológicas, matrizes teóricas menos rígidas, novas formas de pensar o fazer histórico, referenciais de análise mais atuais, novas formas de olhar o social e suas representações. A repercussão sobre a renovação dos conceitos atribuídos ao documento se deu de forma visível, em diferentes áreas do conhecimento.

No entanto, é preciso lembrar que historiadores e pesquisadores, num primeiro momento, alegaram motivos para não considerar e não utilizar a fotografia como documento histórico, fato que na visão de Kossoy (2012) deveu-se à dificuldade, ou mesmo resistência, devido ao fato de a informação contida na imagem fotográfica não ser transmitida por um sistema codificado de signos, em conformidade com os cânones tradicionais da comunicação escrita.

No mesmo diapasão, Etienne Samain (2012), consciente de que as fotografias são portadoras de pensamento e como tal nos fazem pensar, de que são registros da cultura material, do comportamento, hábitos e costumes, alerta para o fato de sermos conduzidos, no mundo ocidental, por uma ordem epistemológica que privilegia o verbal escrito, em detrimento da imagem. Para o autor, somos guiados por uma ordem em que a percepção mágica, que dá início a qualquer construção cultural, foi confrontada pela lógica da escrita linear. Essa lógica acabou por nos impor uma postura mais racional, determinante na relação que o homem passou a ter com o mundo e consigo próprio, no processo de acumulação de conhecimentos e de trocas sociais na qual a escrita teve supremacia.

Mas vale lembrar que não só na História, mas em outras Ciências Sociais e Humanas, o conceito de documento sofreu mudanças significativas: destas destacamos aquelas advindas do pensamento de Otlet (1996) e Briet (1951), referências sempre presentes quando o assunto tratado é a Documentação, área do conhecimento considerada precursora da Ciência da Informação. Para Otlet (1996, p. 43, tradução nossa), a noção de documento "[...] cubre a la vez todos los tipos: volúmenes [livros], folletos, revista, artículos, cartas, diagramas, fotografías, estampas, certificados, estadísticas, incluso discos fotográficos y películas cinematográficas."2 Erudito, buscava dar um caráter científico à Documentação, tendo uma atuação marcante nesse campo, cujo mérito foi lutar pela consolidação de métodos de análise e síntese do conhecimento produzido. Objetivava a universalização do conhecimento e que esta fosse um meio para que se pudesse alcançar a paz entre os homens.

\footnotetext{
2 “"...] cubre a la vez todos los tipos: volúmenes [livros], folletos, revista, artículos, cartas, diagramas, fotografías, estampas, certificados, estadísticas, incluso discos fotográficos y películas cinematográficas."
} 
Os esforços voltados para uma conceituação funcionalista do documento encontraram em Paul Otlet, 1934, um precursor. Propunha que documento, no sentido genérico, abarcasse não só os documentos escritos, mas aqueles caracterizados como iconográficos e audiovisuais. (OTLET, 1996) Ele sonhava com a possibilidade de criar um Repertório Bibliográfico Universal que contivesse todo o conhecimento até então produzido. Em 1934, publica o Traité de documentation, obra que prenuncia conceitos, métodos e sistemas de organização, classificação e difusão dos documentos. Considera que os objetos naturais, artefatos e obras de arte, manuscritos e impressos, inseriam-se no conceito de livro; eles se constituiriam, assim, numa memória materializada da humanidade, incluídos no rol das produções intelectuais dos homens. Biblión ou bibliograma, ou ainda documento, foi o termo proposto por Otlet (1996, p. 43) para designar uma unidade intelectual e abstrata: “[...] que será la unidad intelectual abstracta, pero que se puede encontrar concreta y realmente, pero revestida de modalidades diversas."

Quando Bucceroni e Pinheiro (2009, p. 10) discorrem sobre o Zoom de Otlet na fotografia,_no artigo designado A imagem fotográfica como documento: desideratos de Otlet, afirmam que "[...] a fotografia é para Otlet, o tipo de documento gráfico que melhor exprime o conhecimento humano, por ser o mais realista." Tanto é que Lara (2010), quando expõe a noção de documento e sua significação na trajetória epistemológica da Ciência da Informação, convoca-nos a partilhar da visão de Otlet por este considerar, no seu tempo, a fotografia como documento e a pensar que algo passa a ser documento quando se vê, no objeto inicial, um significado especial que o leva a transformar-se em signo.

A visível crença na objetividade que grassava nesse período, o estigma do mimetismo atribuído à fotografia, consubstanciaram a crença de Otlet (1996, p. 200) na fotografia como mimese do real, levando-o a afirmar que "La fotografía es el medio de representación más realista, aquel cuya objetividad mecánica alcanza la más preciada aproximación cuando se trata de obtner de la naturaleza una imagen en dos dimensiones." Ao sonhar com a criação do Repertório Bibliográfico Universal, ele acreditava também na necessidade da existência de um Repertório Iconográfico Universal, tal era o valor que agregava às imagens e, em especial, à fotografia. Para ele, "No es exagerado decir que hoy en día, con más o menos perfección, rigor científico, gusto artístico el contenido del amplio mundo accesible ao hombre ha sido fotografiado." ${ }^{3}$ (OTLET, 1996, p. 193, tradução nossa)

\footnotetext{
3 “No es exagerado decir que hoy en día, con más o menos perfección, rigor científico, gusto artístico el
} 
No momento em que a questão enfoca a técnica para a produção dos documentos, retornamos a Buceeroni e Pinheiro $(2009$, p. 10) para quem Otlet "[...] especifica três formas de escrever um texto: com as mãos, com uma máquina (datilografia e impressão) ou com a fotografia." Otlet (1996) denominava de fotográfico ao método de criação da imagem fotográfica, considerando-o como substitutivo do método visual, por estar convicto de que a objetividade e a veracidade das coisas residiam no primeiro, enquanto, nesse último, a subjetividade abria espaço para a atribuição de sentidos, para múltiplasinterpretações.

Um pouco mais à frente, na França, Suzanne Briet (1951, p. 7, tradução nossa), no artigo Qu'est-ce que la documentation?, retoma a discussão sobre a noção de documento e documentação, propondo uma releitura dos conceitos de Otlet, de 1934, e da L'Union Française des Organismes de Documentation que advoga ser documento ""[...] toute base de connaissance fixée matériellement et susceptible d'être utilisée pour consultation, étude ou preuve." ${ }^{4}$ A autora propõe outra definição que julga mais atual e abstrata: o documento é “"[...] toute indice concret ou symbolique conservé ou enregistré, aux fins de représenter, de reconstituer ou de prouver un phénomène ou physíque ou intellectuel." ${ }^{5}$ (BRIET, 1951, p. 7, tradução nossa).

A noção de documento como signo, proposta por Briet (1951), para quem o documento se configura como uma evidência física, levou-nos a crer que todo documento é um signo indicial e que arroladas estarão as fotografias na sua conceituação de documento. Para a autora, a fotografia como documento passa a ser um signo por ser o resultado de uma apreensão do real que leva à comprovação de um fato ocorrido, cuja perspectiva é viabilizada pela técnica. Briet (1951, p. 25) adota a expressão produção documentária para indicar a produção de documentos secundários pelas organizações de documentação, a partir dos documentos iniciais, os quais seriam criados pelos autores e apenas conservados pelas organizações de documentação. Ela considera, ademais, documentos secundários as traduções, as análises, os boletins de documentação, arquivos, catálogos, bibliografias, dossiês, fotografias, microfilmes, seleções, sínteses documentárias, enciclopédias, guias de orientação. Como observou Buckland (1997), a materialidade do documento, para Briet (1951), a intencionalidade do sujeito e a forma como é processado, são os critérios que devem

contenido del amplio mundo accesible ao hombre ha sido fotografiado."

4 “[...] toda base de conhecimento fixo materialmente e susceptível de ser utilizado para consulta, estudo ou pesquisa."

5 “[...] todo signo indicial concreto ou simbólico, preservado ou registrado para fins de representação, de reconstituição ou de prova de um fenômeno físico ou intelectual." 
ser usados para defini-lo.

Os conceitos sobre documento emitidos por Briet (1951) são objeto de análise de estudiosos da Ciência da Informação, como os desenvolvidas por Buckland (1991), Lara (2010) e Manini (2011), que lançam luzes sobre a questão. Mesmo tendo partido em defesa de pressupostos que consideram a informação como coisa, a informação como processo e a informação como conhecimento, Buckland (1991), estudioso de Briet, prioriza a materialidade como um fator fundamental para o fazer documentário, tal qual Briet, assim como alerta Lara (2010), quando analisa o documento e a sua significação, na trajetória epistemológica da Ciência da Informação.

Na perspectiva de Buckland, a informação na função de processo e a informação como conhecimento são intangíveis e a informação como coisa se reporta à materialidade da informação. Para Lara (2010, p. 46), “[...] os objetos são considerados informativos como o são os dados, textos, documentos expressos sob forma física ou em ambientes digitais." As proposições de Buckland (1991) e em especial aquela que considera a informação como coisa, levaram Lara (2010) a concluir que a informação como tal se constituiria, assim, em objeto da Ciência da Informação, estando os registros fotográficos inseridos nesse bojo.

Manini (2011), partindo da tríplice concepção de Buckland (1991), faz uma abordagem semelhante, aplicando-a ao documento fotográfico. Ao fazer uma leitura da tríplice concepção do autor sobre ela, a fotografia como informação como coisa remete a objetos fotográficos (negativos de vidro e flexíveis, positivos em papel, diapositivos); a fotografia como informação como processo remete à pesquisa histórica contextualizadora da imagem e sua correlação com outros documentos fotográficos ou textuais, ou outros quaisquer na construção e/ou amplificação de sentido da imagem; e a fotografia como informação como conhecimento remete a resultados de investigações de caráter comparativo entre fotografias e textos históricos. Toda essa formulação induz a autora a considerar que,

Para a Ciência da Informação interessa o significado e o contexto da imagem fotográfica. Portanto, o documento fotográfico precisa passar pelo crivo leitor de produção de sentidos - através do uso de métodos e técnicas existentes - que abarque, também, a localização da imagem fotografada no tempo, no espaço e no organismo pulsante que é o acervo fotográfico enquanto repositório institucional de documentos e memória. (MANINI, 2011, p. 84). 


\section{CONCLUINDO...}

Outras formas de entendimento e de uso da fotografia como documento e meio de observar e fixar o efêmero, pelos quais se pode acompanhar as transformações sociais, os comportamentos e a desaparição do mundo, estão associadas a disciplinas nas quais a fotografia tem sido utilizada largamente, conforme declaração da pesquisadora Cecile Tardy (2016, p. 251, tradução nossa):

Esta capacidade de tornar visível uma extensão espacial através da ferramenta fotográfica nas ciências humanas concerne mais amplamente às ciências da astronomia, da biologia, da medicina, da arqueologia, que têm uma longa tradição na forma de equipar o olho para fazer emergir o invisível ou o não perceptível. ${ }^{6}$

Não só a História e não só as ciências citadas por Tardy (2016) têm feito uso da fotografia nas suas pesquisas científicas. Múltiplas são as vertentes interdisciplinares que já se aperceberam da sua validade como documento nos seus projetos de pesquisa. Dentre as áreas das Ciências Sociais que vêm utilizando-a como fonte de informação, sobressai-se a Antropologia Visual que, na contemporaneidade, alarga seu campo de estudo ao adotar, como uma incitação metodológica, o uso da imagem fotográfica como objeto de investigação.

Como antropólogo e pesquisador, Etienne Samain (2012) levanta questões pertinentes ao uso e apropriação da fotografia, ao valor que lhe é agregado como instrumento de investigação social, como fonte de pesquisa e informação. Seu convencimento o leva a declarar que à imagem fotográfica é devido um lugar "[...] privilegiado da comunicação humana, todavia, não o único, nem o principal, mas o fundador tecnológico que mediava como a fala, a escrita, o cinema e o vídeo, o conhecimento e a representação humana da nossa realidade.” (SAMAIN, 2012, p. 17)

O uso valoroso da imagem fotográfica como documento, na Antropologia, vem sendo preconizado pelo fato da sua capacidade de expressar e dialogar com os modos de vida da sociedade que a produz e, ademais, por viabilizar, não só a interpretação, mas o aprofundamento do universo simbólico dos grupos sociais, favorecendo a reconstituição da história cultural, bem como o acompanhamento do processo de mudança social e sua dinâmica.

\footnotetext{
6 “Cette capacité à donner à voir une étendue spatiale par l'outil photographique dans les sciences humaines rejoint plus largement les sciencies de l'astronomie, de la biologie, de la medicine, de l'archéologie, qui ont une longue tradition dans la maniére d'equiper l'oeil pour faire remonter l'invisible ou lenon-perceptible."
} 
Nos dias atuais, as Ciências Sociais vêm incorporando a fotografia nas suas pesquisas e na prospecção de dados, uma opção que não era acatada em décadas anteriores. Há um reconhecimento da imagem fotográfica como documento produtor de sentido, cuja busca do significado está sujeita ao encontro com a sua referencialidade e seu caráter polissêmico que convida à interpretação, porta aberta à subjetividade. $\mathrm{O}$ desafio que se apresenta a quem se propõe, nas suas pesquisas científicas, a considerar a fotografia como documento é a tensão que se estabelece entre o olhar referencial e a subjetividade, tão bem explicitada por Sontag (1981, p. 220), quando chama a atenção para o fato de que: “A fotografia, na verdade é incapaz de explicar o que quer que seja, é um convite inexaurível à dedução, à especulação e à fantasia."

Se pensarmos que o documento fotografia é fruto de um deslocamento do real capturado pelo olhar e pela técnica do fotógrafo e que esse produto está passível de deduções, especulações e fantasias, o alerta dado por Miriam Manini (2010), pesquisadora da área da Ciência da Informação, deve ser levado em consideração. A autora aconselha que a fotografia deve passar pelo crivo do leitor que, mediante o uso de métodos e técnicas existentes, a situará no tempo e no espaço como produtora de sentidos, fonte de informação e memória, suporte que contém e dá acesso a uma mensagem potencialmente informativa, potencialmente mediadora.

Ao promover a circulação social do conhecimento e por ter reconhecida sua potencialidade informativa e mediadora, a fotografia tem recebido um tratamento documentário especial. O estatuto que a ela vem sendo outorgado como documento tem repercutido na adoção de novos olhares e métodos de análise e interpretação que, na contemporaneidade, têm sido adotados por parte das Ciências Sociais e, em particular, pela Ciência da Informação.

\section{REFERÊNCIAS}

BOURDIEU, Pierre et al. Un art moyen: essay sur les usages sociaux de la photographie. $2^{\text {ème }}$. Paris: Les Éditions Minuit, [2003].

BRIET, Suzanne. Qu'est-ce que la documentation? Paris: Éditions Documentaires, Industrielles et Techniques, 1951.

BUCCERONI, Claudia; PINHEIRO, Lena Vânia Ribeiro. A imagem fotográfica como documento: desideratos de Otlet. In: ENCONTRO NACIONA L DE PESQUISA EM CIÊNCIA DA INFORMAÇÃO, 10., 2009, João Pessoa. Anais [...]. João Pessoa, 2009. p. 1- 
16.

BUCKLAND, Michael. What is a document? Journal of the American Society of Information Science, Maryland, USA, v. 48, n. 9, p. 804-809, Sept. 1997.

BURKE, Peter. Testemunha ocular: história e imagem. Tradução de Maria Xavier dos Santos. Bauru, SP: EDUSC, 2004.

DUBOIS, Philippe. O ato fotográfico e outros ensaios. Tradução Marina Appenzeller. 14. ed. Campinas: Papirus, 2012.

FREUND, Gisèle. La fotografia como documento social. Versión castellana Josep Elias. Barcelona: FotoGGrafía, 2006.

GAMARNICK, Cora. Los usos sociales de la fotografia durante las primeras décadas de su historia. Herramientas de la red de Historia de los Medios, Buenos Aires, año 1, n. 5, p. 1$88,2011$.

KOSSOY, Boris. Fotografia \& história. 4. ed. São Paulo: Ateliê Editorial, 2012.

LARA, Marilda Lopes Ginez de. Documento e significação na trajetória epistemológica da Ciência da Informação. In: FREITAS, Lídia Silva; MARCONDES, Carlos Henrique; RODRIGUES, Ana Célia (org.). Documento: gênese e contexto de uso. Niterói: EduFF, 2010. p. 34-55. (Estudos da Informação, v.1)

LE GOFF, Jacques. Documento/monumento. In: LE GOFF, Jacques. História e memória. Tradução de Irene Ferreira; Bernardo Leitão e Suzana Ferreira Borges. 5. ed. Campinas: Ed. da UNICAMP, 2003. p. 525-541.

MANINI, Miriam Paula. Imagem, memória e informação: um tripé para o documento fotográfico. Domínios da Imagem, Londrina, PR, ano IV, n. 8, p. 77-88, maio 2011.

ORTEGA, Cristina Dotta; LARA, Marilda Lopes Ginez de. A noção de documento: de Otlet aos dias de hoje. DataGramaZero: revista de Ciência da Informação, Rio de Janeiro, v. 11, n. 2, abr. 2010.

OTLET, Paul. El tratado de documentación: el libro sobre el libro: teoría y práctica. Traducción Maria Dolores Ayuso García. [Murcia: Universidad de Murcia], 1996.

ROUILLÉ, André. A fotografia: entre documento e arte contemporânea. Tradução de Constancia Egrejas. São Paulo: Ed. SENAC São Paulo, 2009.

SAMAIN, Etienne (org.). Como pensam as imagens. Campinas: Ed. da UNICAMP, 2012.

SONTAG, Susan. Na caverna de Platão. In: SONTAG, Susan. Ensaios sobre a fotografia. 2. ed. Rio de Janeiro: Arbor, 1981. p. 11-36.

SONTAG, Susan. Sobre fotografia. Tradução de Rubens Figueiredo. São Paulo: Companhia das Letras, 2004. (Sobre a fotografia, 1) 
TARDY, Cécile. Garder trace de l'exposition: les usages mémoriels du dispositif photographhique. In: JOURNÉES SCIENTIFIQUES INTERNACIONALES DU RÉSEAU MUSSI, 3., 2016, Toulouse. Annales [...]. Toulouse: ENFA, 2016. p. 247-262 